\title{
Short Stature in Children Visiting Endocrine Out Patient Department of Kanti Children's Hospital, Nepal
}

\author{
Anupama Kumari Yadav, ${ }^{1}$ Subhana Thapa Karki \\ 'Kanti Children's Hospital, Maharaiguni, Kathmandu, Nepal.
}

\section{ABSTRACT}

\section{Introduction}

The causes of Short Stature in children are different in different countries. It can vary from endocrine to non-endocrine. This study was conducted to identify the causes of short stature in children who are brought in Endocrine Out Patient Department of Kanti Children's Hospital.

\section{Methods}

This is a retrospective study done at Endocrine Out Patient Department of Kanti Children's Hospital for ten year duration. One Hundred and Twenty five Children who were brought with chief complain of not gaining height were included. Children's were evaluated for causes of short stature.

\section{Results}

Male and Female ratio was 1.2:1. The commonest cause seen was Familial Short Stature 41(32.8\%), Constitutional 22(17.6\%), Hypothyroidism 20 (16\%), Syndromic 13 (10.4\%), Skeletal Dysplasia 10 (8\%), Malnutrition 10 (8\%), Chronic Diseases 7 (5.6\%) and Growth Hormone Deficiency 2 (1.6\%).

\section{Conclusions}

This study showed Familial and Constitutional short stature as leading cause of short stature. Hypothyroidism and Malnutrition account for significant percentage which are treatable cause. Down's syndrome(40\%) and Turner Syndrome(7.6\%) are the main genetic causes of short stature.

Keywords: constitutional short stature; familial short stature; pathological short stature.

\section{INTRODUCTION}

Short stature although common can be a challenging problem. ${ }^{1}$ Growth monitoring of children from birth till adulthood provides invaluable information towards diagnosis and management of a whole range of pediatric disorders. ${ }^{2}$ Children are often brought by their parents since they compare it to peer groups. This can be misleading and needs to be confirmed by use of appropriate growth charts whether the child is actually short or not. ${ }^{3}$ 
Short stature is defined by height or length below $3^{\text {rd }}$ centile or less than 2 standard deviation for that specific age and sex. ${ }^{4}$ If the height of the child follows normal growth pattern as per Mean Parental Height (MPH) and no delay in skeletal maturity it is considered normal. ${ }^{5}$ Study done in Nepal has shown the underprivileged children has poor nutrition and has lesser adult height. ${ }^{6}$ This study is conducted to identify the current cause of short stature in Nepalese children who attended the outpatient department of Kanti Children Hospital.

\section{METHODS}

Before commencing data collection for this study, a proposal was submitted to Institutional Review Committee and ethical clearance was taken (39/2020-021). The will of parents or the children was fully respected and informed consent was taken after fully explaining all relevant details. Those who failed to provide consent were excluded. One hundred and twenty five patients with diagnosis of short stature aged from six months to fourteen years were included. Children who were brought with chief complain of not gaining height in endocrine out patient department were included. Data was collected within the duration of ten years from 2011 Jan 01 to 2021 Jan 30. Children who were not brought with above mentioned chief complain even found short stature after examination in hospital were excluded.

Mean Parental Height(MPH) was calculated as, ${ }^{7}$ MPH is calculated by - Boy's - (Father's height in $\mathrm{cm}+$ Mother's height in $\mathrm{cm}+13) / 2$

Girl's - (Father's height in $\mathrm{cm}+$ Mother's height in $\mathrm{cm}-13) / 2$
Target range $=\mathrm{MPH}+-6.5 \mathrm{~cm} .^{8}$

Familial short stature (FSS) is consistent with mid parental height in the absence of nutritional, hormonal, acquired, genetic, and iatrogenic causes and in accordance of bone age. ${ }^{9}$ In Constitutional Delay of Growth and Puberty, growth pattern below the prediction from the parents stature; delay in puberty and/or bone age; positive family history of delayed puberty. ${ }^{10}$ Hormonal: A diagnosis of hypothyroidism was made for patients with low T4 and high thyroidstimulating hormone (TSH) levels, in accordance with the reference range for lab. Syndromic/ Genetic: Short stature in patients with the presence of phenotypic variations. Skeletal Abnormality: Wrongly proportioned bodies or abnormality in skeletal survey. ${ }^{11}$

\section{Tools}

A Clinical Growth chart was used for assessment of weight and height as per age and sex. Laboratory investigation in the form of Complete blood count with ESR, Thyroid Function Test, Growth hormone evaluation if possible, Renal function test, Mantoux test, Gene Xpert, Karyotyping, as needed; Radiological investigation such as Ultrasound of abdomen and pelvis, X-ray of left wrist for bone age evaluation and skeletal survey were done if required.

\section{Data collection and statistical analysis}

During measuring weight and height, it was kept in special consideration to wear light clothes possible, shoes were taken off and hair were untied and kept straight in stadiometer. Children aged from six months to fourteen years were included; those aged less than two years length was taken. After collection of data, SPSS 20 was used for statistical data analysis. 


\section{RESULTS}

Total 125 cases visiting in Endocrine OPD, 70 (56\%) Male and 55 (44\%) Female with chief complain of short stature during January 2011 to January 2021 were taken. The Male : Female ratio was 1.2:1. Minimum age was six months and maximum age was fourteen years with mean age of seven years (Table 1 ).

Table 1. Age and gender of short stature cases

\begin{tabular}{|l|l|}
\hline & Mean (standard deviation) \\
\hline Age & $7.0835(3.98089)$ \\
\hline Male & $70(56 \%)$ \\
\hline Female & $55(44 \%)$ \\
\hline
\end{tabular}

Table 2. Normal Varient and Pathological Causes of Short Stature

\begin{tabular}{|l|l|}
\hline & Frequency (Percentage) \\
\hline Normal Varient & $63(50.4 \%)$ \\
\hline Pathological & $62(49.6 \%)$ \\
\hline
\end{tabular}

Table 2 describes about normal variant(50.4\%) causes of short stature in the form of familial and constitutional delay of growth and puberty. Pathological(49.6\%) causes in the form of hypothyroidism, syndromes, malnutrition, skeletal abnormality, chronic disease and growth hormone deficiency.

Table 3. Different Causes of Short Stature

Frequency (Percentage)

\begin{tabular}{|l|l|}
\hline Familial Short Stature & $41(32.8 \%)$ \\
\hline $\begin{array}{l}\text { Constitutional Delay of } \\
\text { Growth and Puberty }\end{array}$ & $22(17.6 \%)$ \\
\hline Hypothyroidism & $20(16 \%)$ \\
\hline Syndromic & $13(10.4 \%)$ \\
\hline Malnutrition & $10(8 \%)$ \\
\hline Skeletal abnormality & $10(8 \%)$ \\
\hline Chronic disease & $7(5.6 \%)$ \\
\hline Growth Hormone Deficiency & $2(1.6 \%)$ \\
\hline
\end{tabular}

Table3 describes about the differentcauses of short stature. The commonest cause was Familial Short Stature(32.8\%), Constitutional delay of growth and puberty(17.6\%). Among the syndromes, Five cases were of Down's Syndrome(38.4\%), One case of Turner syndrome(7.6\%) and Six cases were other unknown Syndromes. Among the Skeletal dysplasia Four cases were of Achondroplasia(40\%), One case of Morquio Syndrome(MPS IV) and Four cases were other Skeletal dysplasia. The Chronic cases were Congenital Heart Disease, End Stage Renal Disease, Antral Duodenitis, Hypokalaemic Periodic Paralysis, Abdominal Tuberculosis, Hodgkin's Disease, Nasopharyngeal Carcinoma one each.

\section{DISCUSSION}

Short stature is a common cause for which children are brought to hospital. It has also been suggested that early stunting is associated with greater deficits in long-term outcomes than would be expected from the persistent short stature alone. ${ }^{12}$ Growth pattern of a child has been considered as a marker for overall general health of a child and having short stature may signify a serious illness as well. ${ }^{13}$ A study done at Saudi Arabia showed the commonest cause of short stature is familial short stature and other variable were endocrine and nutritional causes. Among endocrine causes growth hormone deficiency was evident. ${ }^{14}$ Another study done at tertiary care hospital of Egypt also showed Growth hormone deficiency as Endocrine cause of short stature and normal variant of growth as other causes such as familial short stature and constitutional growth delay and in some celiac disease. ${ }^{15}$ All these studies showed Familial short stature as commonest cause as shown in our study. 
A study conducted at India showed that the commonest cause of short stature in general OPD was Protein Energy Malnutrition, Chronic Systemic Disease, Chronic Anemia, Skeletal Disorder, Constitutional Short Stature, Endocrine disorders, Intrauterine Growth Retardation, Chromosomal disorders and others in sequence. Same Hospital the causes of short stature at endocrine OPD was Growth hormone deficiency followed by Hypothyroidism, Malnutrition and Chronic diseases. ${ }^{16} \mathrm{~A}$ study conducted at tertiary Care Hospital of Pakistan showed most common cause of Short Stature as Constitutional growth delay and familial short stature. Endocrine causes were Hypothyroidism, Growth Hormone deficiency and Celiac disease. ${ }^{17} \mathrm{~A}$ study done by Muhammad Waqar Rabbani et al in Pakistan showed commonest cause for short stature is Genetic (Familial) followed by Hypothyroidism, Growth Hormone Deficiency, Insulin Dependent Diabetis Mellitus, Constitutional delay, Malnutrition, Celiac Disease, Turner Syndrome and Unknown Syndrome respectively. ${ }^{18}$ Among the endocrine causes Hypothyroidism was commonest cause for short stature in our centre similar to other studies. Finding done in low income countries like India, Pakistan and African regions has suggested constitutional delay and familial short stature as main causes which are similar to our finding. This probably suggest similarity in nutritional status, similar socio-cultural background and genetic make that is the main reason for short stature in this part of the world.

Several genetic disorder can affect in final height. Various chromosomal abnormalities such Turner's syndrome, Noonan syndrome , Down's syndrome can also present as short stature. ${ }^{19}$ In this study Down's syndrome was commonest cause followed by Turner syndrome for short stature.

Among the skeletal dysplasia, achondroplasia is the most common non lethal cause for short stature. ${ }^{20,21}$ This study also showed achondroplasia as commonest cause for disproportionate cause of short stature.

Growth Hormone Deficiency was another common cause which was not same in our study. Due to financial constrains growth hormone evaluation was done in only limited number of cases, resulting in lower percentage of short stature in our study.

Since retrospective study, data was collected from records of patients that may lead to selection bias; those patients whose data were incomplete were left out from this study.

\section{CONCLUSIONS}

Familial Short Stature is found to be the commonest cause of short stature in our children followed by Constitutional delay of Growth and Puberty both of which are Normal Growth Varient. Among the Endocrine causes Hypothyroidism was commonest. Among the syndromes Down's syndrome was common. Achondroplasia as commonest cause among Skeletal abnormalities.

Further studies are required to see the frequency of Growth Hormone deficiency in our children.

\section{ACKNOWLEDGEMENTS}

The authors would like to thank all patients in the study and entire department of Pediatric Endocrinology.

\section{Conflict of Interest: None}




\section{REFERENCES}

1. Cakan N, Kamat D. Short stature in children: a practical approach for primary care providers. ClinPediatr (Phila). 2007 Jun; 46(5):379-85.doi:10.1177/0009922806290597. PMID: 17556733.

2. Lam WF, Hau WL, Lam TS. Evaluation of referrals for genetic investigation of short stature in Hong Kong. Chin Med J (Engl). 2002; 115:607-11.

3. Ranke MB. Towards a consensus on the definition of idiopathic short stature. Horm Res.1996;45(2):64-6. doi: 10.1159/000184851. PMID: 8805048.

4. Polidori N, Castorani V, Mohn A, Chiarelli F. Deciphering short stature in children. Annals of pediatric endocrinology \& metabolism.2020; 25(2), 69-79. https:// doi.org/10.6065/apem.2040064.032.

5. Zhong Cheng Luo, Kerstin Albertsson-Wikland, Johan Karlberg. Target Height as Predicted by ParentalHeightsinaPopulationBasedStudy. PediatricResearch.1998; 44: 563571.https:// doi.org/10.1203/00006450-199810000000166.

6. Farquharson S. M. Growth patterns and nutrition in Nepali children. Arch Dis Child. 1976; 51(3)10. 1136/adc.

7. BenjaminU.Nwosu,MaryM.Lee.Evaluation of Short and Tall Stature in Children. Am Fam Physician. 2008 Sep; 1:78(5):597-604.

8. Cohen P, Rogol AD, Deal CL. Consensus statement on the diagnosis and treatment of children with idiopathic short stature: a summary of the Growth Hormone Research Society, the Lawson Wilkins Pediatric Endocrine Society, and the European
Society for Paediatric Endocrinology Workshop. J Clin Endocrinol Metab. 2008; 93: 4210-4217.

9.RajkumarV,Waseem M.FamilialShort Stature.StatPearls.2021Feb10.https://www. ncbi.nlm.nih.gov/books/NBK559123/.

10. Craig Barstow, Womack. Evaluation of Short and Tall Stature in Children. Am Fam Physician. 2015;92(1):43-5.

11. Maria Wany Louzada Strufaldi, Edina Mariko Koga da Silva, Rosana Fiorini Puccini. Follow-up of children and adolescents with short stature: the importance of the growth rate. Sao Paulo Med. J.2005;123(3). https://doi.org/10.1590/ S1516-31802005000300008.

12. Wells JCK, Devakumar D, Manandhar DS, Chaube SS, Costello A, Osrin D. Association of stunting at 2 years with body composition and blood pressure at 8 years of age: longitudinal cohort analysis from lowland Nepal. Eur J ClinNutr. 2019; 73(2):302-310. 10.1038/s41430-018-0291-y.

13. Rose SR, Vogiatzi MG, Copeland KC. A General Pediatric Approach to Evaluating a Short Child. Pediatrics in Review. 2005; 26(11): 410-20. PMID: 16264029.

14. Al-Jurayyan N NA, Mohamed SH, Al Otaibi HM, Al Otaibi HM, Al Issa ST, Omer HG. Short stature in children: Pattern and frequency in a pediatric clinic, Riyadh, Saudi Arabia. Sudan J Paediatr. 2012; 12(1):79-83. PMID: 27493332:PMCID: PMC4949823.

15. Almontaser Hussein, HekmaFarghaly, Eman Askar, ,KotbMetwalley, Khaled Saad, Asmaa Zahran et al. Etiological factors of short stature in children and adolescents: experience at a tertiary care hospital in Egypt. Ther Adv Endocrinol Metab. 2017; 


\section{8(5):75-80. 10.1177/2042018817707464.}

16. Colaco P, Desai M, Choksi CS. Short stature in Indian children: the extent of the problem. Indian J Pediatr. 1991 Sep-Oct; 58 Suppl 1:57-8. 10.1007/BF02750984.

17. Lashari SK, Korejo HB, Memon YM. To determine frequency of etiological factors in short statured patients presenting at an endocrine clinic of a tertiary care hospital. Pak J Med Sci. 2014; 30(4):858-861. PMCID: PMC4121713PMID: 25097532.

18. Waqar Rabbani M, Imran Khan W, Bilal Afzal A, Rabbani W. Causes of short stature identified in children presenting at a tertiary care hospital in Multan Pakistan. Pak
J Med Sci. 2013; 29(1):53-57. 10.12669/ pjms.291.2688.

19. L Bajracharya. An Integrated Approach to Management of Short Stature. Jour of Diab and Endo Assoc of Nepal 2020; 4 (1):33-39. 10.3126/jdean.v4i1.30075.

20. Pauli, R.M. Achondroplasia: a comprehensive clinical review. Orphanet J Rare Dis. 2019;14(1). https://doi. org/10.1186/s13023-018-0972-6.

21. Chaudhary V, Bano S. Imaging in short stature. Indian journal of endocrinology and metabolism. 2012; 16(5):692-697. https://doi.org/10.4103/2230-8210.100641

Citation: Yadav A, Karki S. Short Stature in Children Visiting Endocrine Out Patient Department of Kanti Children's Hospital, Maharajgunj, Kathmandu, Nepal. JCMS Nepal. 2021; 17(1); 55-60. 